\section{Periocular capillary hemangioma treated with low dose oral propranolol - presentation and outcome of $\mathbf{3 0}$ patients}

\author{
Soma Rani Roy* and Murtuza Nuruddin \\ Orbit Oculoplasty \& Ocular Oncology Department, Chittagong Eye Infirmary \& Training Complex, \\ Chattogram, Bangladesh
}

\section{Abstract}

Purpose: To evaluate the presentation and outcome of periocular capillary hemangioma treated with low-dose oral propranolol.

Method: Thirty cases of periocular capillary hemangioma prospectively studied from $1^{\text {st }}$ June 2015 to $31^{\text {st }}$ May 2017 who received oral propranolol on an outpatient basis. Hemangioma causing any threat to vision or disfigurement was included and age below 3 months and multiple lesions were excluded. Starting dose of propranolol was $1 \mathrm{mg} / \mathrm{kg}$ and increased to $2 \mathrm{mg} / \mathrm{kg}$ after 2 weeks as a maintenance dose. The tapering dose was $1 \mathrm{mg} / \mathrm{kg}$ of body weight before discontinuing the medication. Treatment was continued till the child is 1 year of age or no further change in color or size of the lesion in two successive follow-ups.

Results: Presenting age was $6.36 \pm 3.36$ months (ranged 3-24 months) with female predominance $(70 \%)$. In $86.6 \%$ of cases, the vision was Central Steady and Maintained and cycloplegic refraction showed marked astigmatism in 3 children which resolved after treatment. Forty-six percent of children showed color change as an initial response to treatment. Most children (33.3\%) responded completely within 5 months after starting the treatment. One third patients $(33.3 \%)$ showed $100 \%$ resolution, $50 \%$ showed $90 \%$ to $70 \%$ resolution. Pretreatment and post-treatment lesion size was $1.60 \pm 0.86 \mathrm{~cm}^{2}$ and $0.30 \pm 0.40 \mathrm{~cm}^{2}$ respectively $(p$ - value < $0.0005)$. None showed any significant adverse effect of oral propranolol.

Conclusion: Low-dose oral propranolol is an effective and cost-effective treatment modality for periocular capillary hemangioma and is safe as an outpatient basis.
More Information

*Address for Correspondence:

Dr. Soma Rani Roy, MBBS, DCO, FCPS, FICO, MRCSEd, Head of Orbit Oculoplasty \& Ocular Oncology Department, Chittagong Eye Infirmary \& Training Complex, Chattogram, Bangladesh, Email: dr.somaroy2020@gmail.com

Submitted: December 20, 2021

Approved: December 30, 2021

Published: December 31, 2021

How to cite this article: Roy SR, Nuruddin M. Periocular capillary hemangioma treated with low dose oral propranolol - presentation and outcome of 30 patients. Arch Pathol Clin Res. 2021; 5 : 037-041.

DOI: 10.29328/journal.apcr.1001027

ORCiD: orcid.org/0000-0002-7095-4489

Copyright License: (c) 2021 Roy SR, et al. This is an open access article distributed under the Creative Commons Attribution License, which permits unrestricted use, distribution, and reproduction in any medium, provided the original work is properly cited.

Keywords: Hemangioma; Propanolol; Proliferative stage; Involutional stage

A) Check for updates

OPEn ACCEss

\section{Introduction}

Capillary hemangioma is categorized as a benign vascular tumor in the new classification of International Society for the Study of Vascular Anomalies (ISSVA) [1]. Approximately 1 in 10 children are affected by this type of tumor of varying severity [2]. Capillary hemangioma may present at birth by $33 \%$ to $55 \%$ cases and $90 \%$ cases may become clinically obvious by age of two months [2,3]. Historically females are affected three times more than males and more frequently in premature or low birth weight infants [4]. Risk factors found to be related to this condition are multiple births, advanced maternal age, low birth weight of baby, in vitro fertilization, preeclampsia, placental anomalies, chorionic villus sampling, amniocentesis, prenatal maternal vaginal bleeding, progesterone therapy during early pregnancy, low level of maternal education, mother engaged in manual labor, multiple gestations and maternal medication use in the periconceptional period $[5,6]$. There is also no clear hereditary pattern but a recent study reported positive family history [7]. Though race is not reported as a risk factor but Caucasians are more affected by this tumor [8].

The natural history shows the manifestation of the lesion within the first few weeks of life which grows rapidly in the first year of life known as the proliferative phase and followed by the involutional phase with intermediate stages of varying duration. The literature review showed, most cases of capillary hemangiomas involute spontaneously without intervention and with good cosmesis [9]. 
Small-sized tumors required regular follow-up and observation but treatment is needed to prevent the complications like amblyopia, squint, facial disfigurement, proptosis, exposure keratitis due to proptosis and rarely optic atrophy $[10,11]$. Many treatment options are available for treating capillary hemangioma like systemic and intra-lesional corticosteroid, radiotherapy, laser therapy, vincristine, bleomycin, interferon alfa, cyclophosphamide, imiquimod, etc. But all of these have a variable degree of complications and results [12]. In 2008, Le 'aute '-Labre 'ze, et al, first described the successful and relatively safe use of propranolol in the management of capillary hemangioma [13]. Nowadays it has been chosen as first-line therapy for treating periocular capillary hemangioma [14].

\section{Material and methods}

It was a prospective observational study of 30 cases of periocular capillary hemangioma who received oral propranolol on an outpatient basis from $1^{\text {st }}$ June 2015 to $31^{\text {st }}$ May 2017. The study was approved by the local institutional review board (IRB) and conducted according to the principles of the 2013 revision of the Declaration of Helsinki. Inclusion criteria were children with periocular capillary hemangioma having any threat to vision or disfigurement. Exclusion criteria were children below 3 months of age and who had multiple lesions along with periocular ones. All children were evaluated clinically and no imaging was done. Visual acuity was assessed by CSM (Central, Steady and Maintain) procedure in children below 12 months and by Cardiff Acuity Card in children above 12 months. In every child cycloplegic refraction with atropine $0.5 \%$ ointment was done prior to starting of treatment and at final follow up to evaluate the change in astigmatism. Children were evaluated by a pediatrician for fitness. Prior to starting treatment random blood sugar and chest x-ray were checked. Parents were counseled about the adverse effects of propranolol, preventive measures were taught and informed written consent was taken.

Initially, a dose of propranolol was $1 \mathrm{mg} / \mathrm{kg}$ body weight in 2 to 3 divided doses for 2 weeks then increased to $2 \mathrm{mg} / \mathrm{kg}$ body weight if there was no hypersensitivity or adverse effect of the medicine. Patients have followed up at 4-week intervals until the final follow-up was reached according to the response of treatment. In every follow-up measurement of lesion size, color change and photographic documentation were recorded. Final follow-up meant, no further change in the lesion in successive two follow-ups or if the child is older than one year. Decrease of the size of the lesion or change of color of the hemangioma was defined as success of treatment. SPSS16 software was used for statistical analysis.

\section{Results}

The age range was 3 - 24 months. Most presenting (26.7\%) age was 6 months. Four (13.3\%) children presented above one year of age and one (3.3\%) of them was 24 months. The male: female ratio was $1: 2.7$. The symptom appeared in different ages ranging from 0.5 months to 3 months after birth and in most cases (30\%) they appeared at age of 2 months. The left eye was involved more (60\%) and $6.7 \%$ of cases showed involvement of both eyes. Most of the lesions were located at the upper lid (66.6\%). Both upper and lower lid were affected in $10 \%$ of cases and only one case (3.3\%) showed medial canthal involvement. Fifty percent of children presented without any ocular association and the rest presented with different degrees of ptosis (46\%) and proptosis (4\%). Among 30 children only 3 children presented with marked astigmatism which was reduced after receiving treatment.

The treatment period varied according to the response to treatment. Maximum (33.3\%) responded within 5 months followed by $26.7 \%$ and $23.3 \%$ within 6 months and 7 months respectively. Only one child (3.3\%) took 11 months for effective treatment who presented delayed. At the end of 2 weeks of initial treatment, $46.7 \%$ showed only color change and $40 \%$ showed both changes in color and size. There was no initial change in $13.3 \%$ of cases. The final size of lesion resolution was $100 \%$ (complete) to $50 \%$ (Table 1). Complete resolution was seen in $10(33.3 \%)$ patients followed by $90 \%$ and $80 \%$ resolution in $5(16.7 \%)$ and $6(20 \%)$ children respectively (Figures 1,2). Only one child (3.3\%) showed $50 \%$ resolution but a marked reduction of astigmatism (Figure 3). The pretreatment lesion size was $1.60 \pm 0.86 \mathrm{~cm}^{2}$ and post-

\begin{tabular}{|c|c|}
\hline \multicolumn{2}{|l|}{ Table 1: Presentation and outcome of capillary hemangioma. } \\
\hline Mean age & $6.36 \pm 3.36$ months \\
\hline Mean spherical equivalent & $+3.07 \mathrm{D}$ \\
\hline Pre -treatment & $+0.766 \mathrm{D}$ \\
\hline Post treatment & $4-11$ months \\
\hline Treatment period & 6.83 months \\
\hline Mean & \\
\hline Resolution of lesion & $33.3 \%(n=10)$ \\
\hline Complete (100\%) & $36 \%(n=11)$ \\
\hline $80 \%-90 \%$ & $27.4 \%(n=8)$ \\
\hline $60 \%-70 \%$ & $3.3 \%(n=1)$ \\
\hline $50 \%$ & None \\
\hline Less than $50 \%$ & \\
\hline & \\
\hline & \\
\hline
\end{tabular}

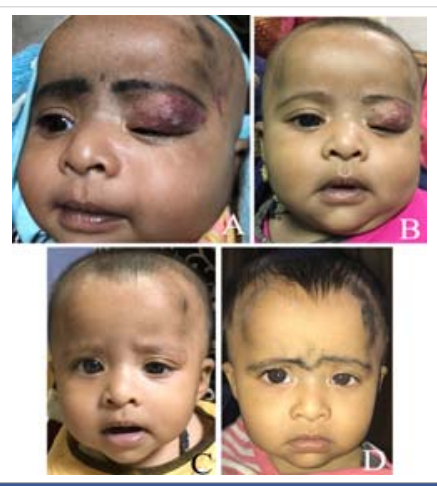

Figure 1: A-D) Complete resolution of the lesion by nine months of age. Treatment started at age of three months. 
treatment was $0.30 \pm 0.40 \mathrm{~cm}^{2}$. The $p$ - value of resolution of the lesion was measured by paired - samples $t$ - test and was less than 0.0005 which is highly statistically significant (Table 2).

\section{Discussion}

Capillary hemangioma is a commonest childhood tumor but still, now there is no standard treatment protocol though different authors consider oral propranolol as the first-line therapy for the treatment of capillary hemangioma [15]. Topical beta-blockers as gel form are used for localized and superficial hemangiomas and nowadays it is also recommended to use in deep lesions [16]. Recently a case of periocular capillary hemangioma is reported complete resolution without recurrence with timolol maleate $0.5 \%$ eye drops [17].

In 2008, Leaute-Labreze first described the role of propranolol for the treatment of severe hemangiomas of infancy. Propranolol, which is a non-selective adrenergic b-blocker, has been used widely for several decades to treat

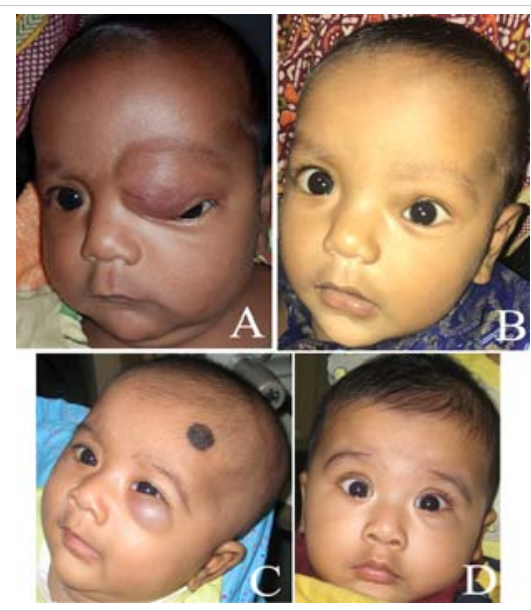

Figure 2: A-B) Pre and post-treatment photos showing eighty percent resolution of the lesion. C-D) Seventy percent resolution of the lesion.

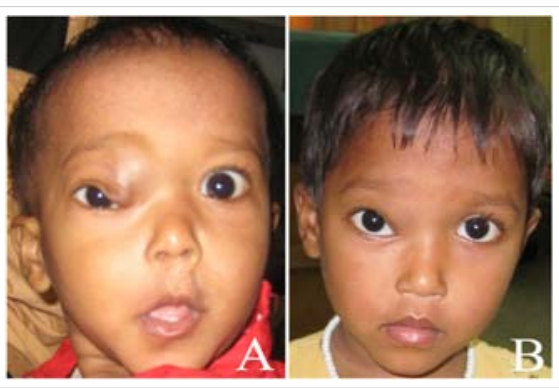

Figure 3: A-B) Delayed response as presented at 12 months but showed a marked reduction in astigmatism.

Table 2: Comparisons between pretreatment and post treatment lesion size.

\begin{tabular}{|c|c|c|c|c|c|}
\hline $\begin{array}{c}\text { Total } \\
\text { no. of } \\
\text { patients }\end{array}$ & $\begin{array}{c}\text { Mean } \\
\text { pretreatment } \\
\text { lesion size in } \\
\mathrm{cm}^{2}\end{array}$ & $\begin{array}{c}\text { Pre- } \\
\text { treatment } \\
\text { Std. } \\
\text { deviation }\end{array}$ & $\begin{array}{c}\text { Mean post } \\
\text { treatment } \\
\text { lesion size in } \\
\mathrm{cm}^{2}\end{array}$ & $\begin{array}{c}\text { Post- } \\
\text { treatment } \\
\text { Std. } \\
\text { deviation }\end{array}$ & $p$ - value \\
\hline 30 & 1.60 & 0.86 & 0.30 & 0.40 & $<0.0005$ \\
\hline
\end{tabular}

Paired - Samples t - test. cardiac, neurologic, endocrine, and other disorders. The exact mechanism of action by which blockers work in capillary hemangiomas was still unclear. Possible mechanisms included a vasoconstrictive effect, decreased expression of growth factors, and hypoxia-induced capillary-endothelial cell apoptosis $[14,18]$. Different case series in the literature described the successful use of propranolol with minimal side effects [18-22].

This study showed the age of presentation was $6.3 \pm 3.36$ months and the most frequent $(26.7 \%)$ presenting age was 6 months. Four children presented above one year of age and one of them was at 24 months. There was also female predominance (1:2.7), which is consistent with the literature (1:3) [5].

We observed that left eye (60\%) predominance and bilateral involvement was only $7 \%$. Saba T, and Alniemi, et al, also showed left (51\%) eye involvement and bilateral was 5\% [23.24]. But Jo Anne, et al. showed equal involvement of both eyes (44\%) [25]. Most lesions (67\%) of the current study were located in the upper lid. Both lid involved in $10 \%$ of cases and one $(3.3 \%)$ presented with medial canthal involvement which was a part of deep orbital hemangioma. Saba et al showed upper lid involvement (86\%) in their study [23]. Literature review also showed a unilateral tumor and upper eyelid predilection [24].

According to the literature, review amblyopia is frequently related to visual deprivation due to the mechanical effect of the mass. Moreover, eyelid mass may alter the topographic parameters of the cornea which results in astigmatism and anisometropia which is another predisposing factor for the development of amblyopia [25]. The current study showed $50 \%$ of patients presented without any ocular association but the rest $50 \%$ were associated with mild to moderate ptosis. Cycloplegic refraction showed marked astigmatism in three children and all these lesions were located at a superomedial part of the upper lid.

Previous investigators have reported successful outcomes with doses ranging from $1 \mathrm{mg} / \mathrm{kg}$ to $5 \mathrm{mg} / \mathrm{kg}$ body weight [26]. In the current study initial dose of oral propranolol was $1 \mathrm{mg} / \mathrm{kg}$ body weight for 2 weeks then increased to $2 \mathrm{mg} / \mathrm{kg}$ body weight. The dose was tapered to $1 \mathrm{mg} / \mathrm{kg}$ bodyweight for 2 weeks at the time of withdrawal. For children older than one year, the treatment ended when there was no change in size or color of the lesion in two subsequent follow-ups. The treatment period varied from 4 months to 11 months. Most children (33.3\%) responded within 5 months. Only one child (3.3\%) who presented at the involutional stage took 11 months for an effective outcome. Though treatment is recommended for up to a year to avoid rebound growth and the need to restart the treatment [27], our experience did not show any rebound growth as we tapered the dose at the end of treatment. 
Current knowledge of pharmacology explains how propranolol causes a change in color and decrease in size. Early effects are vasoconstriction due to decreased release of nitric oxide and the result is color change within 1-3 days. Intermediate effects are due to the blocking of proangiogenic signals like vascular endothelial growth factor, basic fibroblast growth factor, matrix metalloproteinase and result in growth arrest. Long-term effects are induction of apoptosis in proliferating endothelial cells which results in tumor regression [28].

In this study, the tumor size ranged from $0.4 \mathrm{~cm}^{2}$ to 3.96 $\mathrm{cm}^{2}$ seven $(23.3 \%)$ patients had a lesion of 2 or more than $2 \mathrm{~cm}^{2}$ diameter. Three patients $(10 \%)$ had more than $3 \mathrm{~cm}^{2}$ diameter and largest one was $3.96 \mathrm{~cm}^{2}(2.2 \mathrm{~cm} \times 1.8 \mathrm{~cm})$. Complete resolution was observed in $33 \%(n=10)$ cases. $17 \%(n=5)$ showed near about complete resolution that is $90 \%$ resolution of lesion followed by $80 \%$ resolution in $20 \%$ $(n=6)$ cases. Rest $20 \%(n=6)$ patients showed $70 \%, 7 \%$ $(n=2)$ showed $60 \%$ and $3 \%(n=1)$ showed $50 \%$ resolution. Haider, et al. have defined various grades of success [19]. An 'excellent' result was qualified as $\geq 50 \%$ reduction in the size of the hemangioma, 'good' as a decrease in size of $<50 \%$, 'fair' as no further growth, and 'poor' as continued growth or intolerable adverse effects. According to this classification, our 29 patients showed excellent results and the rest showed good results. The pretreatment lesion size was $1.60 \pm 0.86$ $\mathrm{cm}^{2}$, post-treatment was $0.30 \pm 0.40 \mathrm{~cm}^{2}$ and the pairedsample t-test showed that the $p$-value was $<0.0005$ which is highly statistically significant( Table 2 ).

According to a different study, the resolution time varied from 2 months to 6 months [14,19]. In this study it ranged from 4 months to 11 months. Most children (33\%, $n=10$ ) responded within 5 months of treatment either completely or near completely followed by $26 \%(n=8)$ within 6 months and 23\% $(n=7)$ within 8 months. One patient (3\%) responded earlier that is within 4 months and another one (3\%) responded delayed and took 11 months. The child who responded in delay, presented at 12 months of age and only $50 \%$ reduction of the tumor but astigmatism reduced markedly. Common adverse effects of propranolol are hypotension, hypoglycemia, bradycardia and bronchoconstriction. In our study, there was no significant drug-related adverse effect. Only 2 children had to stop propranolol for a few days as they were suffering from severe cough and cold. We counseled every parent properly about the adverse effects of medicine and what to do if any adverse situations occur.

In our observation oral propranolol is effective in each case but may be more effective if the treatment is started at an earlier age that is in the proliferative stage. Further study is needed with a big sample.

\section{Conclusion}

In this observational study, it has been noted that oral propranolol is very effective in resolving capillary hemangioma. All the patients were treated on an outpatient basis and there was no significant side effect. Low-dose oral propranolol, therefore, can be considered as safe first-line therapy in the treatment of periocular capillary hemangioma and the best result can be achieved if treatment is started in the proliferative stage of the disease. In our experience, it is cost-effective as the cost of medicine is less and patients can be safely treated on an outpatient basis.

\section{References}

1. Dasgupta R, Fishman SJ. ISSVA classification. Semin Pediatr Surg. 2014; 23: 158-161.

PubMed: https://pubmed.ncbi.nlm.nih.gov/25241091/

2. Buckmiller L, Dyamenahalli U, Richter GT. Propranolol for airway hemangiomas: Case report of novel treatment. Laryngoscope. 2009; 119: 2051-2054.

PubMed: https://pubmed.ncbi.nlm.nih.gov/19650125/

3. Garza G, Fay A, Rubin PA. Treatment of pediatric vascular lesions of the eyelid and orbit. Int Ophthalmol. Clin. 2001; 4: 43-55. PubMed: https://pubmed.ncbi.nlm.nih.gov/11698737/

4. Haik BG, Karcioglu ZA, Gordon RA, Pechous BP. Capillary hemangioma (infantile periocular hemangioma) Surv Ophthalmol. 1994; 38: 399-426.

PubMed: https://pubmed.ncbi.nlm.nih.gov/8009426/

5. Dickison P, Christou E, WargonO. Aprospective study of infantile hemangiomas with a focus on incidence and risk factors. Pediatr Dermatol. 2011; 28: 663-669.

PubMed: https://pubmed.ncbi.nlm.nih.gov/21995808/

6. Bauland CG, Smit JM, Scheffers, Bartels $R H$, van den Berg $P$ Zeebregts $\mathrm{CJ}$, et al. Similar risk for hemangiomas after amniocentesis and transabdominal chorionic villus sampling. J Obstet Gynaecol Res. 2012; 38: 371-375.

PubMed: https://pubmed.ncbi.nlm.nih.gov/22229643/

7. Chen XD, Ma G, Chen $H, Y e X X$, Jin YB, et al. Maternal and perinatal risk factors for infantile hemangioma: A case-control study. Pediatr Dermatol. 2013; 30: 457-461.

PubMed: https://pubmed.ncbi.nlm.nih.gov/23278441/

8. Bang GM, Setabutr P. Periocular capillary hemangiomas: Indications and options for treatment. Middle East Afr J Ophthalmol. 2010; 17: 121-128.

PubMed: https://pubmed.ncbi.nlm.nih.gov/20616917/

9. Bang GM, Setabutr P. Periocular Capillary Hemangiomas: Indications and Options for Treatment. Middle East Afr J Ophthalmol. 2010; 17: 121-128.

PubMed: https://pubmed.ncbi.nlm.nih.gov/20616917/

10. Grabb WC, Dingman RO, O'Neal RM, et al. Facial hamartomas in children:Neurofibroma, lymphangioma, and hemangioma. Plast Reconstr Surg. 1980; 66: 509-527.

PubMed: https://pubmed.ncbi.nlm.nih.gov/7208665/

11. Hernandez JA, Chia A, Quah BL, Seah LL. Periocular capillary hemangioma: Management practices in recent years. Clin Ophthalmol. 2013; 7: 1227-1232

PubMed: https://pubmed.ncbi.nlm.nih.gov/23814460/

12. Hermans DJJ, Bauland CG, Zweegers J, van Beynum IM, van der Vleuten CJM. Propranolol in a case series of 174 patients with complicated infantile haemangiomas: indications, safety and future directions. Br J Dermatol. 2011; 168: 817-843.

PubMed: https://pubmed.ncbi.nlm.nih.gov/23278381/ 
13. Levitt M, Coumou AD, Groeneveld L, Freling NJM, van der Horst CM, et al. Propranolol as first line treatment in orbital infantile haemangiomas. Orbit Informa J. 2014; 33: 178-183.

PubMed: https://pubmed.ncbi.nlm.nih.gov/24568543/

14. Le'aute-Labre ze C, Dumas de la Roque E, Hubiche T, Boralevi F, Thambo JB, et al. Propranolol for severe haemangiomas of infancy. N Engl J Med. 2008; 158: 2649-2651.

PubMed: https://pubmed.ncbi.nlm.nih.gov/18550886/

15. vanderHorstCM,SaeedP.PropranololasFirst-Line Treatmentin Orbital Infantile Haemangiomas: A Case Series. Orbit. 2014; 33: 178-183. PubMed: Phttps://pubmed.ncbi.nlm.nih.gov/24568543/

16. Xue K, Hildebrand GD. Deep periocular infantile capillary hemangiomas responding to topical application of timolol maleate, 0.5\%, drops. JAMA Ophthalmol. 2013; 131: 1246-1248.

PubMed: https://pubmed.ncbi.nlm.nih.gov/23846584/

17. Jefferson RJ, Hildebrand GD. Topical timolol treatment for periocular infantile haemangioma in the developing world. Trop Doct. 2019; 49: 246-248.

PubMed: https://pubmed.ncbi.nlm.nih.gov/31014195/

18. Missoi TG, Lueder TG, Gilbertson K, Bayliss SJ. Oral propranolol for treatment of periocular infantile hemangiomas. Arch Ophthalmol. 2011; 129: 899-903.

PubMed: https://pubmed.ncbi.nlm.nih.gov/21402978/

19. Haider KM, Plager DA, Neely DE, et al. Outpatient treatment of periocular infantile haemangiomas with oral propranolol. J AAPOS. 2010; 14: 251-256.

PubMed: https://pubmed.ncbi.nlm.nih.gov/20603059/

20. Al Dhaybi R, Superstein R, Milet A, Powell J, Dubois J, et al. Treatment of periocular infantile hemangiomas with propranolol: a caseseries of 18 children. Ophthalmology. 2011; 118: 1184-1188. PubMed: https://pubmed.ncbi.nlm.nih.gov/21292326/

21. Thoumazet F, Leaute-Labreze C, Colin J, Mortemousque B. Efficacy of systemic propranolol for severe infantile haemangioma of the orbit and eyelid: a case study of eight patients. $\mathrm{Br} \mathrm{J}$ Ophthalmol. 2012; 96: 370-374.

PubMed: https://pubmed.ncbi.nlm.nih.gov/21673014/

22. Cornish KS, Reddy AR. The use of propranolol in the management of periocular capillary haemangioma-a systematic review. Eye. 2011; 25:1277-1283.

PubMed: https://www.ncbi.nlm.nih.gov/pmc/articles/PMC3194317/

23. Saba T. Alniemi BS, Griepentrog GJ, DiehI N, Mohney BG. Incidence and Clinical Characteristics of Periocular Infantile Hemangiomas. Arch Ophthalmol. 2012; 130: 889-894.

PubMed: https://www.ncbi.nlm.nih.gov/pmc/articles/PMC3673779/

24. Alniemi ST, Griepentrog GJ, Diehl N, Mohney BG. Incidence and Clinical Characteristics of Periocular Infantile Hemangiomas. Arch Ophthalmol. 2012; 130: 889-893.

PubMed: https://www.ncbi.nlm.nih.gov/pmc/articles/PMC3673779/

25. Hernandez JA, Chia A, Quah BL,Seah LL. Periocular capillary hemangioma: management practices in recent years. Clinical Ophthalmology Clinical Cannady SB, Kahn TA, Traboulsi El, Koltai PJ. PHACE syndrome: Report of a case with a glioma of the anterior skull base and ocular malformations. Int J Pediatr Otorhinolaryngol. 2006; 70: $561-564$

26. Pope E, Krafchik BR, Macarthur C, Stempak D, Stephens D, et al. Oral versus high-dose pulse corticosteroids for problematic infantile haemangiomas: a randomized, controlled trial. Pediatrics. 2007; 119: e1239-47.

PubMed: https://pubmed.ncbi.nlm.nih.gov/17485449/

27. Taylor H R. Infantile Periocular Haemangioma: Optimising the Therapeutic Response. Paediatr drugs. 2016; 18: 157-160. PubMed: https://pubmed.ncbi.nlm.nih.gov/27043724/

28. Storch $\mathrm{CH}$, Hoeger $\mathrm{PH}$. Propranolol for infantile haemangiomas: insights into the molecular mechanisms of action. Bri J Dermatol. 2010; 163: 269-274.

PubMed: https://pubmed.ncbi.nlm.nih.gov/20456345/ 